The main statistical difficulty lies in obtaining suitably matched controls, since the holistic approach takes so many factors into consideration that no two individuals and no two treatment programmes are ever alike. Add to that the considerable difference between alternative and modern styles of assessment, and it is plain that the solution may lie in alternative methods of evaluation rather than in attempting to impose an orthodox solution on an unorthodox problem.

For obvious reasons there can never be a truly double blind trial to compare acupuncture with aspirin, but despite recent reports ( 30 July, p 326) there can be little doubt which is normally safer in skilled hands. Safety and cost are both factors to be taken into account when assessing the potential place of alternative medicine in the National Health Service. Acupuncture, osteopathic manipulation, homoeopathy, hypnosis, and clinical ecology in combination could replace up to a third of conventional management in general practice. Furthermore, the constructive use of preventive health measures using morbidity registers, at risk groups, and health education programmes could dramatically change the face of general practice in a manner that might be cheaper than at present and would certainly be safer. It is also what our patients would like.

The interest shown by vocational trainees (30 July, p 337) may well extend eventually to a portfolio of these subjects as a complement to their orthodox training. The interest is not so much a "flight from science" as a quest for a safer route to health than orthodox medicine, which is more geared to the treatment of major diseases than the alleviation of minor complaints and the through road to health.

We need to know whether or not prescribing habits (and even morbidity patterns) change with the incorporation of alternative methods in general practice. This can be achieved by experienced practitioners who have previously undertaken vocational training and are now in a position to compare orthodox and alternative styles of practice. In these circumstances short courses are not the complete answer, and the regulations in relation to prolonged study leave may need adjustment in order to take full advantage of the prospects which alternative medicine offers to objectively critical enthusiasts.

David M SMITH

Runcorn WA7 2HY

** We have received many other letters on alternative medicine and have been able to publish only a selection.-ED, $B M F$.

\section{Changing pattern of poisoning in children}

SIR,-The introduction of child resistant containers, and particularly the extension of their use in 1981 to include all solid dose medicines, has been criticised. ${ }^{1}$ It is therefore important to determine whether such containers are effective in preventing childhood poisoning. In the absence of any controlled studies we are dependent on retrospective and prospective uncontrolled studies that are riddled with many confounding variables. Dr G R Lawson and colleagues of Newcastle, who have been most prominent in the study of childhood poisoning, have reported their recent findings (2 July, p 15). They again show a definite fall in salicylate poisoning after the introduction of child resistant packaging in 1976. Their much quoted original report ${ }^{2}$ supported the extension of the use of child resistant containers.

We recently reviewed childhood poisoning in Dundee and also showed a decline in salicylate poisoning, but this decline started in 1970, four years before child resistant packaging was introduced. It is recognised that salicylate has become less fashionable as a simple analgesic and the decreased availability is thought to explain the decline in salicylate self poisoning in adults. ${ }^{3}$ The change in availability may also have had some effect on childhood salicylate poisoning and thus influenced the results of a study on this type of poisoning.

The success of child resistant packaging in preventing salicylate poisoning is in strong contrast to its failure to reduce childhood paracetamol poisoning. Dr Lawson and his colleagues suggest that this failure is due to prescribing paracetamol as an elixir to children. This is not packaged in a child resistant container. They provide no information suggesting that this is the preparation most commonly ingested in childhood poisoning. Meredith and his colleagues ${ }^{4}$ reported that in the age range 1 to 4 years less than $40 \%$ of childhood paracetamol poisonings were from paracetamol elixir, the remainder being from either paracetamol tablets or paracetamol in combination with dextropropoxyphene. $\mathrm{Dr}$ Lawson does not show a decrease in paracetamol poisoning in 1981 when both of these last two preparations were packaged in child resistant containers. In contrast to salicylate there has been a steady increase in the purchase and prescribing of paracetamol ${ }^{5}$ and this greater availability may have counteracted the effects on paracetamol poisoning of child resistant packaging.

Dr Lawson's data show that the total number of poisoning episodes has declined during the study period. Unfortunately, he does not break these figures down into medicinal and non-medicinal poisoning, but the text suggests that this decline is predominantly in the medicinal group. We have similar data for Dundee, showing a steady decline in admissions after childhood poisoning, the decline being greatest for ingestion of medicines, with no pronounced trend in nonmedicinal poisoning. Such a decrease was shown for medicines that were packaged in child resistant containers and also for benzodiazepines, tricyclic drugs, and barbiturates, which were not packaged in child resistant containers. Unlike the Newcastle group, we think that the previous preventive measures, such as publicity campaigns emphasising the need for care in handling and storing medicines, suitable warnings on labels of all medicines, and the suggestion to return all unused medicines, have made the general public more aware of the risk of childhood poisoning.

We agree with Dr Lawson that medical practitioners should always be aware of the risk of childhood poisoning and take care in prescribing. We found in Dundee that there was an increase in medicinal poisoning in single parent households. We found that $43 \%$ of the drugs ingested by children in such households were anxiolytic, hypnotic, and antidepressant drugs, and $50 \%$ of all diazepam ingestions took place in families where there was a single parent. Prescribing such medicines to a harassed single parent is common practice but is undesirable as it does not solve the underlying problem; it simply makes the parent less aware of his or her surroundings and less alert to the danger of an inquisitive child swallowing the medicine.

J S FORSYTH

Department of Child Health,

M E HAYMAN

Ninewells Hospital,
Dundee DD1 9SY

' CRCs: for and against. Pharmaceutical fournal 1981; 2 Sibert JR, Croft AW, Jackson RH. Child resistant packaging and accidental child poisoning. Lancet
parting 1977 ;ii :289-90.

foudfoot AT, Park J. Changing pattern of drugs used for self-poisoning. Br Med F $1978 ; \mathrm{i}: 90-3$.

Meredith TJ, Newman B, Goulding R. Paracetamo

poisoning in children. Br Med $\mathcal{Y} 1978$;ii :478-9.
Spooner JB, Harvey JG. The history and usage

paracetamol. I Int Med Res 1976;4 (suppl 4):1-6.

\section{Squatter's palsy}

SIR,_-"Saturday night palsy" or "crutch palsy" due to compression of the radial nerve in the upper arm is well known, ${ }^{1}$ and leads to weakness in the action of triceps, extensor carpi radialis longus, extensor carpi radialis brevis, and extensor carpi ulnaris. Dr C W Buckley and Dr T R C Davis reported bilateral ulnar and radial nerve palsies as a complication of childbirth using a birthing stool (16 July, p 180).

We wish to describe a case of palsy following childbirth in the squatting position. A 32 year old primipara was admitted to our unit in established labour. She was keen to deliver in the squatting position. Within two hours the cervix was fully dilated, all other recordings were normal, and she had a strong desire to push. For one hour before delivery she was continuously supported from the rear by her husband who held her under both armpits.

She had a spontaneous delivery after a second stage lasting 15 minutes. Ten minutes after delivery she complained of weakness in her left arm and poor grip of her left hand. This was severe enough to prevent her holding her son safely. On examination there was no sensory loss but there was pronounced weakness in the muscles enabling extension at the elbow and wrist, with a resultant wrist drop and impaired grip. Over the following six days the muscle power was steadily regained.

It may be that support for patients who wish to use "natural birth positions" should be intermittent rather than continuous, as described here, if squatter's palsy is to be avoided.

J M MACPHERSON A J GORDON

Elsie Inglis Memorial Maternity

Hospital,
Abbeyhill, Edinburgh EH8 8HT

' Sunderland S. Nerve and nerve injuries. 2nd ed. 1978:820-42. Edinburgh: Churchill Livingstone,

\section{Should homosexuals be vaccinated} against hepatitis $B$ virus?

SIR,-We agree with Professor $M$ W Adler and his colleagues (21 May, p 1621) that a clear policy on vaccination against hepatitis $\mathrm{B}$ virus infection is necessary. We have completed a population based study of hepatitis B virus infection in Paddington and North Kensington, and preliminary analysis of our data indicates that the problem is much greater than previous studies suggest.

We defined a case as anyone from whom a blood sample was positive for hepatitis $B$ surface antigen (HBsAg), an acute case as someone who cleared the antigen from his blood within six months, and a 